\title{
EL DESARROLLO DE DULCINEA Y LA EVOLUCIÓN DE DON QUIJOTE
}

Claro está que no hay ningún "desarrollo" de Dulcinea en la obra de Cervantes en el sentido corriente de la palabra, ya que no existe, ni siquiera como un personaje "ausente", en la novela. Creación de Don Quijote basada en Aldonza Lorenzo (que sí pertenece al mundo de la novela aunque nunca aparece), Dulcinea está a la disposición de cualquiera de los personajes de la novela para manipular al caballero, pero se presta igualmente a las manipulaciones conscientes o inconscientes del protagonista mismo. "El desarrollo de Dulcinea" se referirá aquí a las facetas del desarrollo de Don Quijote reflejadas en su actitud hacia ella y a la manera de verla en distintos momentos de su trayectoria vital en el transcurso de la novela. A diferencia de otras transformaciones de la realidad practicadas por Don Quijote, Dulcinea es una creación consciente sin las restricciones de una presencia activa dentro de la acción, así como el sueño de la cueva de Montesinos es una creación inconsciente. Ella será en cualquier momento lo que Don Quijote quiere que sea, con más libertad que molinos de viento, manadas de ovejas o barcos abandonados. Ocupa, además, el lugar central que corresponde a la dama que inspira a los caballeros andantes de sus amados libros de caballerías, es la persona a quien quiere impresionar con sus hazañas, la personificación de su "público"'.

Aparece inicialmente Dulcinea como un accesorio imprescin-

${ }^{1}$ Como ha notado José Escarpanter, "esta especial condición de no intervenir de modo directo en la urdimbre novelesca y vivir sólo en el plano abstracto de las referencias, posibilita dentro de la técnica narrativa la creación de distintas imágenes del personaje, estructuradas según el pensar, el ver y el sentir de quienes trazan sus retratos" ("Trayectoria de Dulcinea", Crítica hispánica, 7 [1985], p. 10). Aquí sólo nos interesa la perspectiva variable de Don Quijote. 
dible para la carrera de caballero andante que proyecta Don Quijote. Después de idear el proyecto y requerir los accesorios más importantes, como son el yelmo y el caballo, "se dio a entender que no le faltaba otra cosa sino buscar una dama de quien enamorarse" (I, 1; las cursivas son mías, aquí y en adęlante). Dada esta motivación, su "devoción" es rutinaria e imitativa: "no durmió Don Quijote, pensando en su señora Dulcinea, por acomódarse a lo que habia leido en sus libros"' (I, 8). Como ha notado Julio Rodríguez Luis, se dirige a Dulcinea en un discurso imaginario "como si verdaderamente fuera enamorado" $(\mathrm{I}, 2)^{2}$. Don Quijote está dispuesto a reemplazarla, para conseguir lo que quiere, por la hija de cualquier "rey de los cristianos o de los paganos [que] tenga guerra y tenga hija hermosa" (I, 21). En cuanto a la castidad de su dama, no le preocupa a Don Quijote el ejemplo de Angélica con Medoro, "porque mi Dulcinea del Toboso osaré jurar que no ha visto en todos los días de su vida moro alguno, así como él es, en su mismo traje" (I, 26). Sancho nos asegura que Aldonza "tiene mucho de cortesana" (I, 25), y Don Quijote está dispuesto a jurar que "se está hoy como la madre que la parió" (I, 26).

La poesía que semejante dama inspira en el caballero está a la altura de esta concepción inicial. Entre los versos que grabó Don Quijote en los árboles de Sierra Morena estaban éstos:

y así, hasta henchir un pipote, aquí lloró don Quijote ausencias de Dulcinea del Toboso (I, 25).

Vivaldo, el caballero que acompaña a Don Quijote al entierro de Grisóstomo, suscita la caracterización más elaborada que el caballero proporciona en la Primera parte, pidiendo "nombre, patria, calidad y hermosura":

su nombre es Dulcinea; su patria, el Toboso, un lugar de la Mancha; su calidad, por lo menos, ha de ser de princesa, pues es reina y señora mía; su hermosura, sobrehumana, pues en ella se vienen

2 “Dulcinea a través de los dos Quijotes", NRFH, 18 (1965-1966), p. 380. Añade Rodríguez Luis, además, que "Dulcinea aparece con el valor de adición a unos preparativos derivados de una decisión del todo independiente de ella"' (p. 379). Citaré el Quijote según la ed. de JoHn JAY ALLEN, Cátedra, Madrid, 1984. 
a hacer verdaderos todos los imposibles y quiméricos atributos de belleza que los poetas dan a sus damas: que sus cabellos son oro, su frente campos elíseos, sus cejas arcos del cielo, sus ojos soles, sus mejillas rosas, mármol su pecho, marfil sus manos, su blancura nieve, y las partes que a la vista humana encubrió la honestidad son tales, según yo pienso y entiendo, que sólo la discreta consideración puede encarecerlas, y no compararlas $(I, 13)$.

La banal serie de tópicos petrarquistas rutinarios "has the effect of reducing Dulcinea to a grotesque mosaic of sculptural materials", como ha dicho Charlotte Stern ${ }^{3}$, pero es sobre todo la adición de "las partes que a la vista humana encubrió la honestidad" que encomienda Don Quijote a la "discreta consideración" de Vivaldo lo que coloca la descripción definitiva, si bien inconscientemente, dentro del género antipetrarquista. "El etcétera es de mármol", me parece recordar haberlo leído en Góngora, al describir éste a una dama.

El comentario sobre la calidad de Dulcinea es tan egocéntrico y tan poco informativo que Vivaldo insiste: "el linaje, prosapia y alcurnia querríamos saber'. Acosado así, Don Quijote ofrece una lista de veinticinco familias a las que no pertenece Dulcinea, asegura que su familia podría venir a ser el comienzo de un linaje ilustre, y cierra la discusión diciendo: "no se me replique en esto" (I, 13). "Don Quijote's response is evasive", dice Charlotte Stern. Más bien defensiva, diríamos. 'Píntola en mi imaginación como la deseo, así en la belleza como en la principalidad', le revela Don Quijote a Sancho en Sierra Morena (I, 25), y compara su preferencia por Dulcinea a la preferencia de una viuda por un amante en una anécdota popular: "para lo que yo le quiero, tanta filosofía sabe, y más, que Aristóteles". Con exquisito cuidado va insistiendo Cervantes en el frío utilitarismo de esta concepción original: una "cosa que le faltaba", sustituible por otra, tabula rasa que no tiene que ser ni saber nada, hembra que puede servirle para dar comienzo a un linaje. Stern tiene toda la razón al notar que "Don Quijote conveys the subjectivity of his image of Dulcinea by emphasizing the first person: "Por lo que yo quiero", "bástame a mí pensar y creer», "Yo me hago cuenta», "yo imaginon" "4 y aun por encima del énfasis en lo subjetivo va la clara "cosificación" utilitaria.

${ }^{3}$ Charlotte Stern, "Dulcinea, Aldonza, and the theory of speech acts", $H, 67$ (1984), 64-65.

4 Ibid., p. 66. 
Al final de la Primera parte, es difícil no estar de acuerdo con la caracterización de Don Quijote que ha hecho recientemente Peter Russell: "his total devotion to the imaginary Dulcinea is altogether egocentric" "5. O con la afirmación de Anthony Close de que "the hero's attitude towards Dulcinea is a comic sham and his attitude towards the people who question him about her is absurd sophistry"6. El concepto que tiene Don Quijote de Dulcinea en la Primera parte se limita a lo instrumental, lo convencional y lo físico.

Según Stern, “Don Quijote never varies his image of Dulcinea. In Chapter 64 of the second part she is still the beautiful princess she was at the beginning of his journey"' (p. 70). Es verdad, y también es verdad que Don Quijote es todavía el flaco cincuentón loco, pero es igualmente verdad que en la Segunda parte el protagonista cambia radicalmente, y a medida que cambia Don Quijote, cambia su concepto de Dulcinea.

El texto fundamental para el concepto de Dulcinea que tiene Don Quijote en la Segunda parte surge en el capítulo 32, cuando repite la duquesa el interrogatorio de Vivaldo de la Primera, pidiendo primero "que le delinease y describiese [. . . ] la hermosura y facciones de la señora Dulcinea". Como ha señalado Close, empieza Don Quijote de una manera ridícula, tomando al pie de la letra una imagen figurada de la tradición del amor cortés: " $\mathrm{Si}$ yo pudiera sacar mi corazón y ponerlo ante los ojos de vuestra grandeza, aquí, sobre esta mesa y en un plato [...]'”. Le parece a Close que "his defence to the Duke's questions about Dulcinea's social status is much the same as that which he offers to similar questions [by Vivaldo] in Part I, 13''; cree además que "this implies that his mental image of Dulcinea has in no way changed from what it was in early Part I"' . Atiéndase, sin embargo, a la manera de relatar Don Quijote el episodio del encantamiento de Dulcinea y a su reacción al alegato de la duquesa, basado en la Primera parte, de que el caballero "la engendró y parió en su entendimiento". La respuesta de Don Quijote aquí se distingue tajantemente de su contestación a Vivaldo:

Ni yo engendré ni parí a mi señora, puesto que la contemplo como conviene que sea una dama que contenga en sí las partes que pue-

${ }^{5}$ Peter Russell, Cervantes, Oxford University Press, Oxford, 1985, p. 46.

6 Anthony Close, 'Don Quixote's love for Dulcinea", $B H S, 50$ (1973), p. 252.

${ }^{7}$ Id. 
dan hacerla famosa en todas las del mundo, como son: hermosa sin tacha, grave sin soberbia, amorosa con honestidad, agradecida por cortés por bien criada y, finalmente, alta por linaje [...] (II, 32).

Todo esto es muy convencional, por supuesto, y Ciose opina que el énfasis particular de Don Quijote en "alta por linaje" es el detalle que comprueba la intención irónica fundamental ${ }^{8}$. Pero ha habido un cambio significativo en los puntos de referencia: predomina claramente ahora el carácter de Dulcinea sobre la descripción física. Insiste el duque, tal como lo había hecho Vivaldo, en la cuestión del linaje, y la réplica de Don Quijote difiere ya marcadamente:

Dulcinea es hija de sus obras, y [...] las virtudes adoban la sangre, y [...] en más se ha de estimar y tener un humilde virtuoso que un vicioso levantado. Cuanto más que Dulcinea tiene un jirón que la puede llevar a ser reina de corona y cetro; que el merecimiento de una mujer hermosa y virtuosa a mayores milagros se estiende (II, 32).

La descripción de Dulcinea que Don Quijote le había presentado a Vivaldo quedó limitada a lo físico, pero lo que ahora se esfuerza el caballero por inventar es el carácter de Dulcinea. La respuesta a la pregunta sobre el linaje de la dama sigue esa misma línea, y el contraste con el episodio de Vivaldo es aun más claro. A pesar de afirmar posteriormente que "Dulcinea es principal y bien nacida, y de los hidalgos linajes que hay en el Toboso [...] a buen seguro que no le cabe poca parte a la sin par Dulcinea", la respuesta en este momento no es ya la defensiva de antes. Establece agresivamente un contraste implícito con la obra/linaje de los duques. En "hija de sus obras" suena el recuerdo de la Primera parte, y la anfibología de jirón demuestra que Don Quijote maneja aquí el idioma con una maestría que contrasta vivamente con chuscas equivocaciones como jurar que Dulcinea "se está hoy como la madre que la parió" en la Primera parte.

Hay un contraste igualmente fuerte entre la poesía que Don Quijote le dedica a Dulcinea en la Segunda parte - por convencional que sea- y los versos grotescamente ramplones de la Primera ("así, hasta henchir un pipote", I, 261). Son versos traducidos de un madrigal de Pietro Bembo:

8 Ibid., p. 253. 
Amor, cuando yo pienso

en el mal que me das, terrible y fuerte, voy corriendo a la muerte, pensando así acabar mi mal inmenso;

mas en llegando al paso

que es puerto en este mar de mi tormento

tanta alegría siento,

que la vida se esfuerza y no le paso.

Así el vivir me mata,

que la muerte me torna a dar la vida.

¡Oh condición no oída

la que conmigo muerte y vida trata! (II, 68).

Los cambios que he querido apuntar aquí son, obviamente, sólo reflejos de los cambios más profundos que sufre Don Quijote en el transcurso de sus aventuras. Según cambian sus motivaciones, cambia la dama que las "encarna" (si se me permite la perversión del término). "Religión es la caballería”, afirma Don Quijote en el capítulo 8 de la Segunda parte.

Hemos de matar en los gigantes a la soberbia; a la envidia en la generosidad y buen pecho; a la ira, en el reposado continente y quietud del ánimo; a la gula y al sueño, en el poco comer que comemos y en el mucho velar que velamos; a la lujuria y lascivia, en la lealtad que guardamos a las que hemos hecho señoras de nuestros pensamientos; a la pereza, con andar por todas las partes del mundo $[\ldots](\mathrm{II}, 8)$.

Hasta Ciose caracteriza este pasaje como portador de "sabiduría"9

La arrogancia de la Primera parte es reemplazada por una creciente "mesura". "Todo el mundo se tenga, si todo el mundo no confiesa que no hay en el mundo todo doncella más hermosa que la emperatriz de la Mancha, la sin par Dulcinea del Toboso", les había exigido Don Quijote a los mercaderes en el capítulo 4 de la Primera parte. Cuando le pidieron un retrato de la dama, replicó así: "Si os la mostrara, ¿qué hiciérades en confesar una verdad tan notoria? La importancia está en que sin verla lo habéis de creer, confesar, afirmar, jurar y defender'. Hay que comparar esto con su respuesta a las dudas del Caballero de la Blanca Luna con respecto a la supremacía de la belleza de Dulci-

${ }^{9}$ Ibid., p. 254. 
nea: "yo osaré jurar que jamás habéis visto a la ilustre Dulcinea; que si visto la hubiérades, yo sé que procurárades no poneros en esta demanda, porque su vista os desengañara de que no ha habido ni puede haber belleza que con la suya comparar se pueda"' (II, 64).

Como hemos visto, el concepto que formula Don Quijote de Dulcinea inicialmente se limita a lo instrumental, lo convencional y lo físico. Hacia el final de la Segunda parte ha llegado a ser un dechado de virtud, íntegramente ligada a la cordura que ya empieza el caballero a saber que ha perdido: "si mi Dulcinea saliese de los [trabajos] que padece, mejorándose mi ventura y adobándoseme el juicio, podría ser que encaminase mis pasos por mejor camino del que llevo" (II, 57). Como apunta Ruth El Saffar, "the effort to conflate Dulcinea and Aldonza Lorenzo is the subject of Don Quixote, Part II"10. Las percepciones de Don Quijote del mundo que lo rodea se vuelven cada vez más "normales" a medida que va recobrando la cordura. Paradójicamente, sin embargo, Dulcinea se hace a la misma vez menos corpórea.

Algo de esto había visto Emilio Goggio al escribir, en 1952, que "there are in reality two different Dulcineas, as there are two distinct and inseparable Don Quijotes, or rather [...] each of these characters plays a dual role [... ]"11. Pero Goggio no parece haber visto el desarrollo de Don Quijote implícito en esta doble dualidad.

La orientación moral de la nueva visión de Don Quijote de la caballería andante en la Segunda parte va parejas con la nueva orientación de su concepto de Dulcinea. Por mi parte, yo no encuentro indicio de ninguno de estos dos elementos en la Primera parte, y me parece que los críticos "duros", ahora representados ante un público más amplio por el libro de Russell, tendrán que enfrentarse más directamente con las señales de unos cambios fundamentales en Don Quijote, sobre todo en los capítulos posteriores a la estancia con los duques, y los cambios en su concepto de Dulcinea; es decir que tendrán que incorporar de alguna manera estos cambios dentro de la visión inalterablemente cómica del libro que nos han ofrecido. A pesar de darnos un análisis basado meticulosamente en el texto, Ciose no nos ofrece ninguna cita de

${ }^{10}$ Ruth EL Saffar, Beyond fiction. The recovery of the femenine in the novels of Cervantes, University of California Press, Los Angeles, 1984, p. 59.

${ }^{11}$ Emilio Goggio, "The dual role of Dulcinea in Don Quijote de la Mancha', MLQ, 13 (1952), p. 285. 
los últimos dieciocho capítulos, sobre todo el encuentro entre Don Quijote y Sansón en su papel de Caballero de la Blanca Luna (II, 64). Russell sólo ve un "kindly victor" en el arrogante y vengativo Sansón de este episodio. Don Quijote sigue siendo loco en II, 64 , pero sólo de acuerdo con la nueva perspectiva cuidadosamente preparada por el texto podemos entender la disposición del caballero a morir a manos del Caballero de la Blanca Luna por afirmar la supremacía de Dulcinea del Toboso como algo más que una locura sin sentido.

John J. Allen

University of Kentucky 